\title{
Microstructure and wear behaviour of powder and suspension hybrid $\mathrm{Al}_{2} \mathrm{O}_{3}-\mathrm{YSZ}$ coatings
}

\author{
James W Murray ${ }^{1}$, Alessandro Leva ${ }^{1}$, Shrikant Joshi ${ }^{2}$, Tanvir Hussain ${ }^{1}$ \\ ${ }^{1}$ Faculty of Engineering, University of Nottingham, UK \\ ${ }^{2}$ University West, Trollhättan, Sweden
}

Corresponding author: Tanvir Hussain, tanvir.hussain@ nottingham.ac.uk, 01159513795

\begin{abstract}
Suspension based plasma sprayed coatings can yield superior microstructural and tribological properties compared to conventional powder based plasma sprayed coatings. This study investigates a new hybrid method, using simultaneous spraying from powder and suspension, to produce composite coatings using alumina and yttria stabilised zirconia (YSZ), with potentially excellent wear and thermal properties. Dry sliding wear showed the alumina suspension-YSZ suspension coating yielded half the specific wear rate of the alumina powderYSZ suspension, explained by preferential gamma alumina formation and increased porosity in the latter. Both YSZ-containing samples showed superior toughness and wear rate than simple alumina powder and suspension coatings.

Keywords: A suspensions; $\mathrm{B}$ composites; $\mathrm{C}$ wear resistance; $\mathrm{D} \mathrm{Al}_{2} \mathrm{O}_{3}$
\end{abstract}




\section{Introduction}

Plasma spraying is a thermal spraying process which uses a feedstock powder supplied into a plasma jet, which is then rapidly heated and accelerated. Molten and semi-molten particles collide on the substrate surface, rapidly solidifying into a coating. Sub-micron powder feedstock in plasma spraying can produce fine microstructures with improved mechanical properties; however, sub-micron sized powder can become clogged in the powder feeding system. Suspension plasma spraying (SPS) is a modification of conventional plasma spraying which uses a liquid medium - i.e. a suspension - to transport micron and sub-micron sized particles from the feeder to the plasma flame. The use of suspension, either water or ethanol, prevents particles from agglomerating and clogging the nozzle. Additionally, coatings sprayed from finer feedstocks are expected to yield enhanced mechanical properties due to the finer coating microstructure [1].

Despite the advantages of using SPS, deposition rates are typically much lower in comparison to conventional plasma spraying techniques, impacting industrial viability [2, 3]. Joshi et al. [4] proposed a hybrid approach for harnessing the advantages of conventional powder and liquid feedstocks, using separate, individually controllable injection systems. Plasma spraying employing the above approach with a suspension-powder hybrid feedstock combines the benefits of finer microstructure from the former and higher deposition rates from the latter.

Zirconia toughened alumina (ZTA) is often used as a die or cutting tool material, bearing components, bushings, valve seats and pump components given its high strength, fracture toughness and wear resistance. For example, the fracture toughness of ZTA has been measured at 6.0 MPa.m ${ }^{1 / 2}$ compared to 4.2 and 5.4 for alumina and zirconia, respectively [5]. The small grain size of YSZ leads to superior hardness and strength [6], as well as to higher density and better cohesion, which are fundamental properties for the improvement of wear resistance [7]. Zirconia is well known as a toughening agent and has been frequently added to enhance the 
mechanical properties of alumina $[8,9]$. Yttria stabilised zirconia is often used as opposed to pure zirconia to promote transformation toughening [10]. Transformation of the tetragonal phase to monoclinic can result in $3-4 \%$ volume expansion, resulting in excessive tensile residual stresses, however retaining the tetragonal phase via the stabilisation provided by yttria can avoid this phenomenon and hence maximise the toughening effect [11]. ZTA composite coatings have been prepared by thermal spraying technique before. An alumina-40 wt.\% YSZ plasma sprayed coating showed superior dry sliding wear behaviour in comparison to plasma sprayed alumina and YSZ individually by a factor of 8 and 60, respectively [12]. This is explained by the improved cohesive strength between splats as well as the phase transition toughening mechanism associated with tetragonal zirconia formation. Other work has shown that the amorphous content and, hence, properties of plasma sprayed ZTA composite coatings depend on the zirconia content. For example, $40 \mathrm{wt} . \%$ zirconia in ZTA yielded a notably higher amorphous content compared to $35 \mathrm{wt} . \%$ and $45 \mathrm{wt} . \%$ zirconia, explained by the closeness of the $40 \mathrm{wt} . \%$ zirconia coating to the eutectic point of the alumina-zirconia binary system [13].

To deposit a uniform distribution of two material types via a thermal spraying process, hybrid approaches were considered. The aim of the work is to evaluate the influence of a hybrid approach of a combined powder and suspension delivery on mechanical and wear properties of plasma sprayed zirconia-toughened alumina coatings. By characterising the properties and performance of coatings manufactured via a hybrid method, a new more tailorable approach to achieving specific composite coating properties can be considered in future. The deposited coatings were evaluated in terms of microstructure and porosity, hardness, fracture toughness as well as dry sliding wear resistance against an alpha alumina counterbody. 


\section{Experimental}

\subsection{Materials and Coating Deposition}

Four coatings were sprayed using plasma spraying (PS), with a Mettech Axial III high power plasma torch (Northwest Metterch Corp, Vancouver, Canada). For suspension based spraying, a Nanofeed 350 suspension feeder was used, and for powder delivery, a Uniquecoat PF50WL (Richmond, USA) was used. To spray simultaneously suspension and powder based feedstocks, a novel hybrid setup was used, in which two separate feed systems allow delivery of suspension based particles and powder particles directly into the plasma torch at the same time. A schematic of the process is shown in Figure 1. The same set up can also be utilized to feed either the powder or the suspension alone by turning on just one of the feed systems.

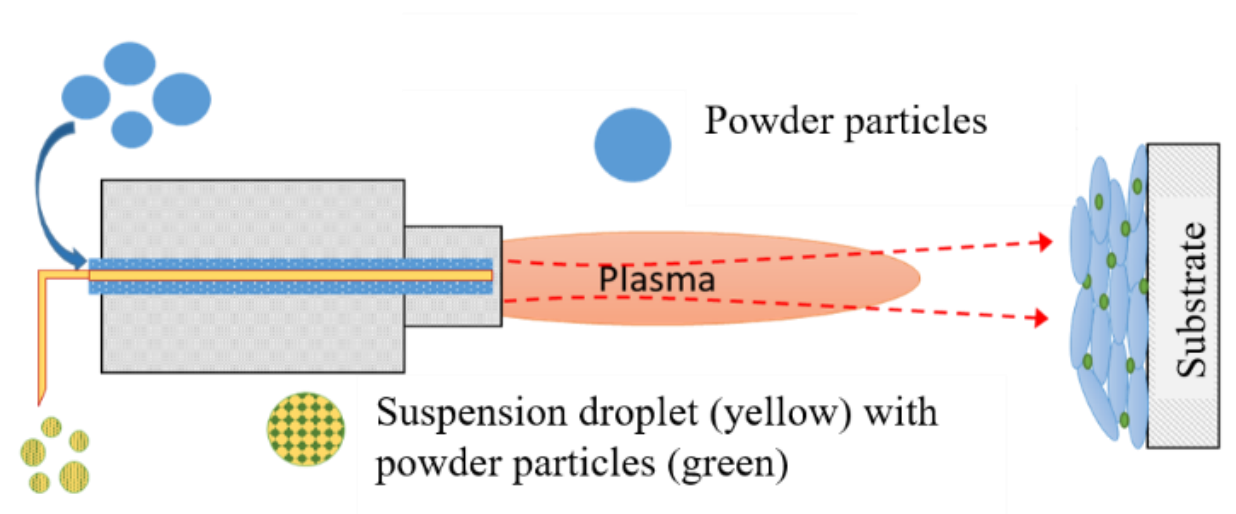

Figure 1 Axial feed plasma spray torch with simultaneous injection of powder and suspension feedstocks

The coatings sprayed along with designations were: alumina powder (AP), alumina suspension (AS), hybrid alumina suspension with YSZ suspension (AS-YS), and hybrid alumina powder with YSZ suspension (AP-YS). Domex 355 (Mn1.5P0.25V0.2C0.1FeBal) steel substrates, with a bond coat of NiCoCrAlY (Amperit 410, H.C. Starck GmbH, Germany), were used for all coatings. The substrates were grit blasted prior to application of the bond coat to enhance adhesion of the coating. While the alumina powder was commercially procured (Amperit 740, 
H.C. Starck GmbH, Germany), the suspension feedstock was prepared using the relevant powder, alumina or YSZ, in an ethanol suspension with $25 \mathrm{wt} \%$ solid load content by Treibacher Industrie AG, Austria. In the AS-YS and AP-YS coatings, 20 wt.\% YSZ was fed as a suspension, with the remaining part being either alumina powder or suspension. Plasma spraying parameters for all four coatings are shown in Table 1.

Table 1 Plasma spraying parameters for alumina powder, alumina suspension, alumina powder- YSZ suspension and alumina suspension- YSZ suspension

\begin{tabular}{|c|c|c|c|c|}
\hline & $\begin{array}{c}\text { AP (Alumina } \\
\text { powder) }\end{array}$ & $\begin{array}{c}\text { AS (Alumina } \\
\text { suspension) }\end{array}$ & $\begin{array}{c}\text { AP-YS } \\
\text { (Alumina } \\
\text { powder/YSZ } \\
\text { suspension) }\end{array}$ & $\begin{array}{c}\text { AS-YS } \\
\text { (Alumina } \\
\text { suspension/YSZ } \\
\text { suspension) }\end{array}$ \\
\hline Spray Distance (mm) & 150 & 100 & 150 & 100 \\
\hline $\begin{array}{c}\text { Powder feed rate, } \\
\mathrm{g} / \mathrm{min}\end{array}$ & 50 & - & 40 & - \\
\hline $\begin{array}{c}\text { Suspension feed rate, } \\
\mathrm{ml} / \mathrm{min}\end{array}$ & - & 40 & 40 & 40 \\
\hline Power, kW & 109 & 122 & 124 & 122 \\
\hline Current, A & 230 & 220 & 230 & 220 \\
\hline
\end{tabular}

\subsection{Materials characterisation}

Sprayed samples were cut with a precision cutting saw with silicon carbide circular disc, and subsequently mounted in a conductive resin with a mounting press to produce cross-sectioned samples. The cross-sectioned samples were ground using four stages of grinding with a progressively decreasing grit size, after which they were diamond polished using first a $6 \mu \mathrm{m}$ and then a $1 \mu \mathrm{m}$ diamond grit.

Scanning electron microscopy (SEM) (JEOL 6490, Japan) was used to study sample morphology and microstructure, using both secondary electron (SE) and back-scattered electron imaging (BSE) modes. Coating thicknesses were determined by taking five measurements at intervals of approximately $0.5 \mathrm{~mm}$ using SEM images.

X-ray diffraction (XRD) was used to determine the phase compositions of the coatings. A Siemens D500 diffractometer was used with $\mathrm{Cu}-K \alpha$ radiation with a wavelength of $0.154 \mathrm{~nm}$ 
at settings of $40 \mathrm{kV}$ and $25 \mathrm{~mA}$. $2 \theta$ angles from $20^{\circ}$ to $95^{\circ}$ were used, with a step size of $0.05^{\circ}$ and a step time of 2 seconds.

To measure porosity, three SEM images in SE mode at x750 magnification were taken for each sample, and then using ImageJ software (National Institutes of Health, USA) the pores were identified using image thresholding in order to quantify area of pores and therefrom $\%$ area of porosity.

\subsection{Microhardness and Fracture toughness}

For microhardness measurement, indentation was performed with a Vickers hardness indenter. Ten indents, evenly distributed along the coating cross-sections were made with an applied load of $50 \mathrm{gf}$. This load was chosen given the absence of crack formation, and hence full energy dissipation was into the indent only, while the indent size was sufficiently large to be measured accurately.

To calculate fracture toughness, a 200 gf load was used, yielding cracks at indent tips. Ten indents were made at regular intervals across the cross-sectional length of the coatings, which were used to calculate an average toughness value.

Given the lamellar nature of thermally sprayed coatings, fracture upon indentation only took place horizontally, hence the calculated toughness represents horizontal fracture toughness. The following equation was used to calculate fracture toughness:

$K_{I C}=0.16\left(\frac{c}{a}\right)^{-1.5}\left(H \cdot a^{\frac{1}{2}}\right)$

where $K_{I C}$ is fracture toughness $\left(\mathrm{MPa} \mathrm{m}^{1 / 2}\right), c$ is the average length of the cracks from the indents' tips $(\mu \mathrm{m}), a$ is the half average length of the indent's diagonal $(\mu \mathrm{m})$, and $H$ is the Vickers hardness measured from the indent (MPa) [14]. 


\subsection{Wear Testing}

A CETR UMT-3 mini-tribometer (Struers, USA) was used to conduct ball-on-flat dry sliding wear tests. The counterbody was an alpha alumina ball of $6.3 \mathrm{~mm}$ diameter. The surface roughness of the coatings was controlled via sequential grinding and polishing under the same conditions as for the cross-sectional samples to a mirror finish, to eliminate the effect of surface roughness on wear behaviour as well as to improve the measurability of the wear track profiles. Each sample underwent wear testing for 30 minutes each time at a load of $10 \mathrm{~N}$, with a stroke length of $5 \mathrm{~mm}$, and a sliding speed of $10 \mathrm{~mm} / \mathrm{s}$. For each test condition, two samples were tested and an average value has been reported herein.

Wear track profiles were measured with a Taylor Hobson Talysurf CLI 1000 (Leicester, UK) contact profilometer with a lateral resolution of $0.5 \mu \mathrm{m}$. Five profiles were taken for each wear track, from which cross-sectional areas were taken and multiplied by track length to calculate the wear volume. Specific wear rate was calculated via the following equation:

$S W R=\frac{V R}{S D \times F}$

where $S W R$ stands for specific wear rate $\left(\mathrm{mm}^{3} / \mathrm{Nm}\right), V R$ represents the volume removed $\left(\mathrm{mm}^{3}\right), S D$ is the sliding distance $(\mathrm{m})$, and $F$ is the force applied $(\mathrm{N})$. Counterbody wear rates were also measured by optical microscopy of their wear scars, by measurement of area of wear patch visible and then converting it to volume loss via simple geometric equations for volume of a sphere.

\section{Results}

\subsection{Microstructural Analysis}

Figure 2 shows back-scattered electron images of all coatings, revealing the good bonding of the coatings with the bond-coat above the substrate. Table 2 shows data of porosity and thickness. The AP sample yielded the thickest coating in comparison to the three other types, but also the most porous. 

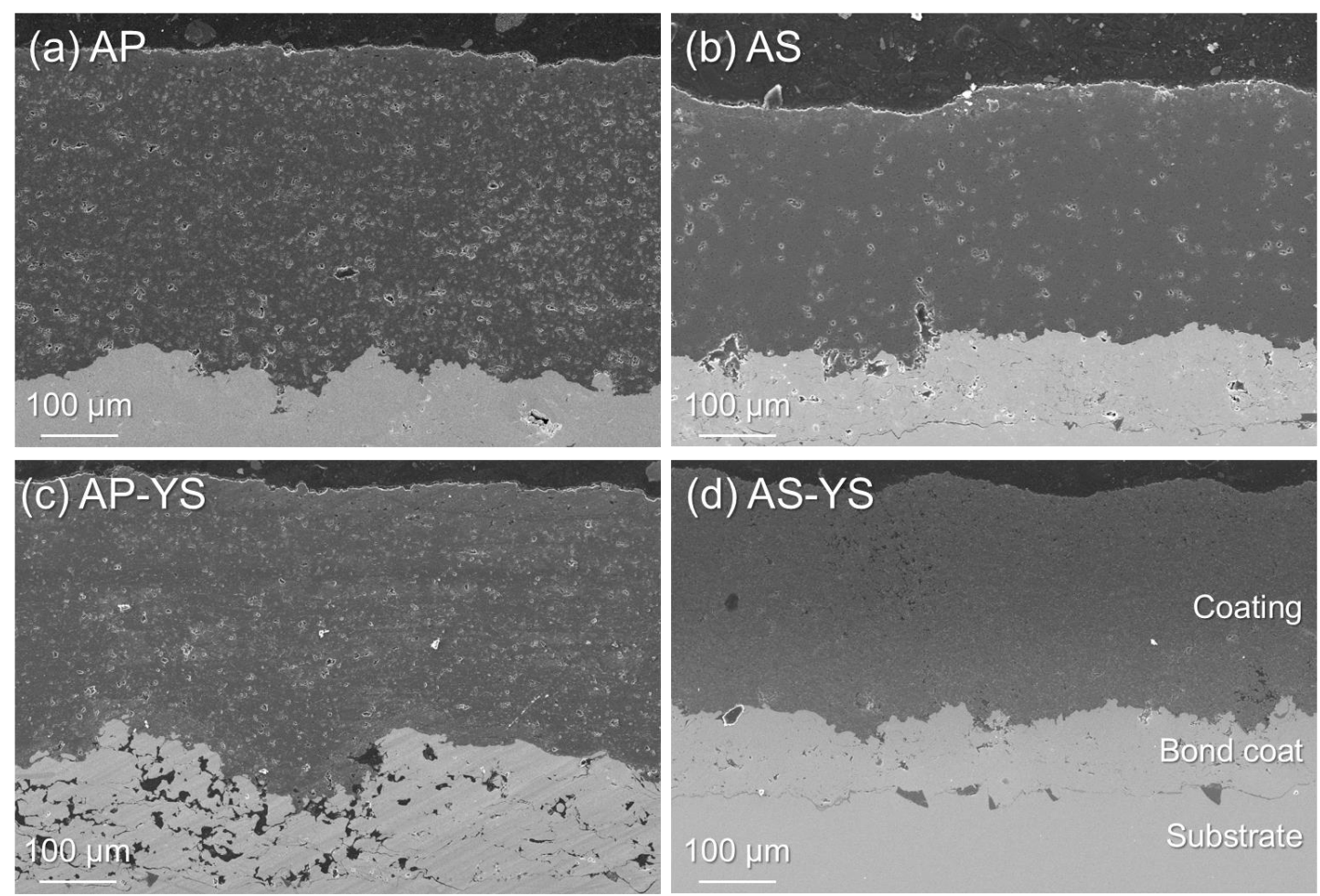

Figure 2: Secondary electron SEM images showing cross-section views of (a) alumina powder (AP), (b) alumina suspension (AS), (c) alumina powder-YSZ suspension (APYS) and (d) alumina suspension-YSZ suspension (AS-YS)

Table 2 Mechanical properties, porosity and thickness of all coatings

\begin{tabular}{|l|l|l|l|l|}
\hline & AP & AS & AP-YS & AS-YS \\
\hline Porosity $(\%$ & $7.53 \pm 0.45$ & $2.72 \pm 0.33$ & $2.69 \pm 0.21$ & $1.43 \pm 0.09$ \\
area) & & & & \\
\hline $\begin{array}{l}\text { Coating } \\
\text { thickness }(\boldsymbol{\mu m})\end{array}$ & $432.98 \pm 11.75$ & $330.67 \pm 13.45$ & $361.42 \pm 23.36$ & $307.03 \pm 15.35$ \\
\hline
\end{tabular}

The coatings sprayed using powder alumina feedstocks - i.e. AP and AP-YS yielded the thickest coatings, of $\sim 430$ and $\sim 360 \mu \mathrm{m}$, respectively. The pure suspension based coatings AS and AS-YS yielded thinner coatings of $\sim 330$ and $\sim 307 \mu \mathrm{m}$ respectively. Interestingly, the alumina powder (AP) sprayed coating contained by far the highest porosity of the four coatings 
at $\sim 8 \%$ by area, in comparison to the other coatings at between 1 and $3 \%$. The AS-YS coating yielded the lowest porosity at $1.4 \%$.

Figure 3 shows high magnification secondary electron images of the cross-sections of all four coatings. The most porous coating - AP, exhibits regions of large pores ( 10 $\mu \mathrm{m}$ diameter), and a relatively homogenous distribution of small pores prevalent in all regions of the coating. When compared to AS and AS-YS, the frequency of small pores is significantly reduced in both the suspension coatings, and can be explained by the fact that the coating is comprised of smaller, dense, and more numerous splats. YSZ infiltration into the pores resulting from powder-derived splats possibly explains the three-fold lower porosity in the AP-YS sample compared to the AP coating.
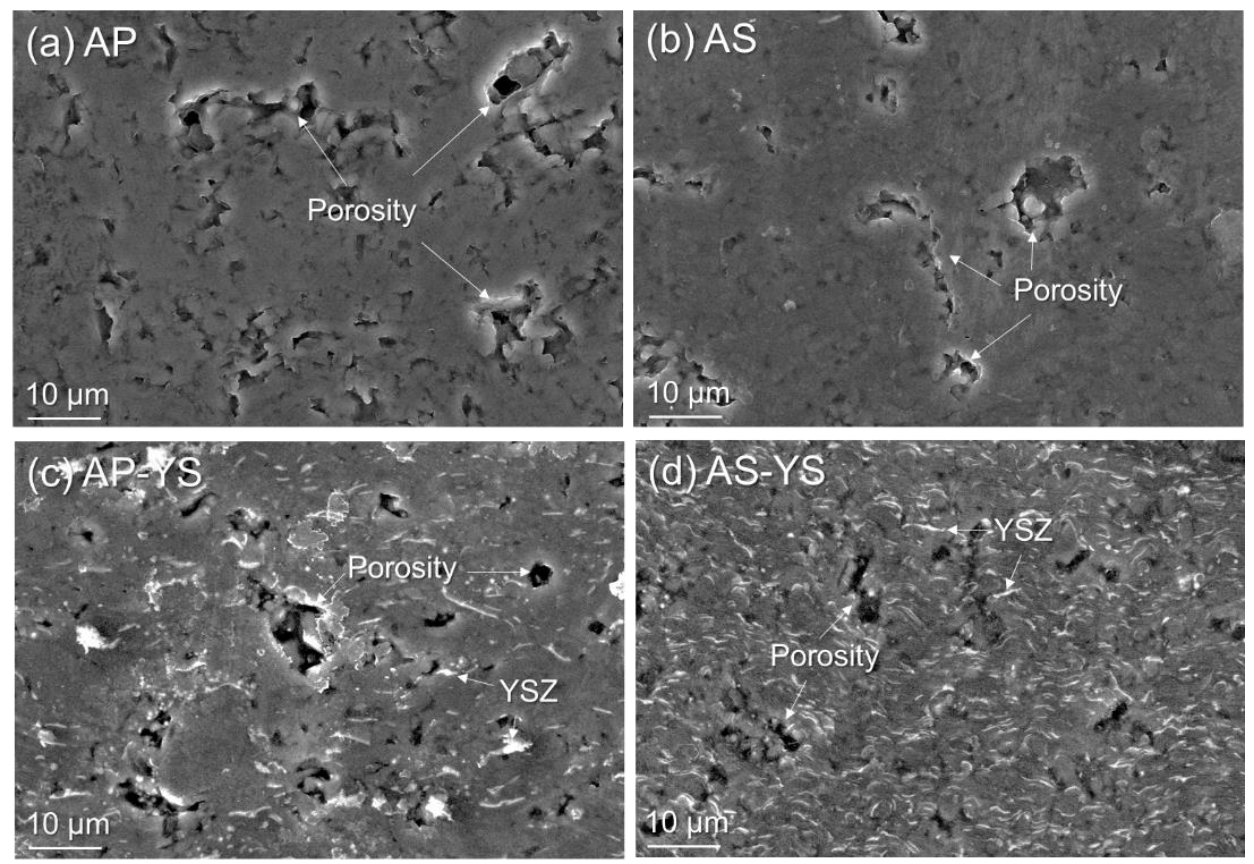

Figure 3: High magnification SE images of (a) alumina power (AP), (b) alumina suspension (AS), (c) alumina powder-YSZ suspension and (d) alumina suspension-YSZ suspension and revealing YSZ as bright regions

Additionally, in Figure 3, YSZ appears as bright white regions visible in (c) and (d). In the ASYS sample the YSZ is distributed more homogeneously compared to the AP-YS sample, 
reflecting the larger splat size associated with the alumina powder in the AP-YS. Additionally, in the AP-YS, there are regions of much larger YSZ particles than present in the rest of the coating and in the AS-YS coating, which can perhaps also be explained by preferential infiltration of the larger pores formed by the powder-derived alumina splats. Therefore, it is likely that the porosity influences the reinforcement properties of the YSZ in the alumina matrix by the above mechanism.

\subsection{XRD Characterisation}

XRD was conducted on all sprayed samples, and the XRD diffraction patterns are shown in Figure 4.

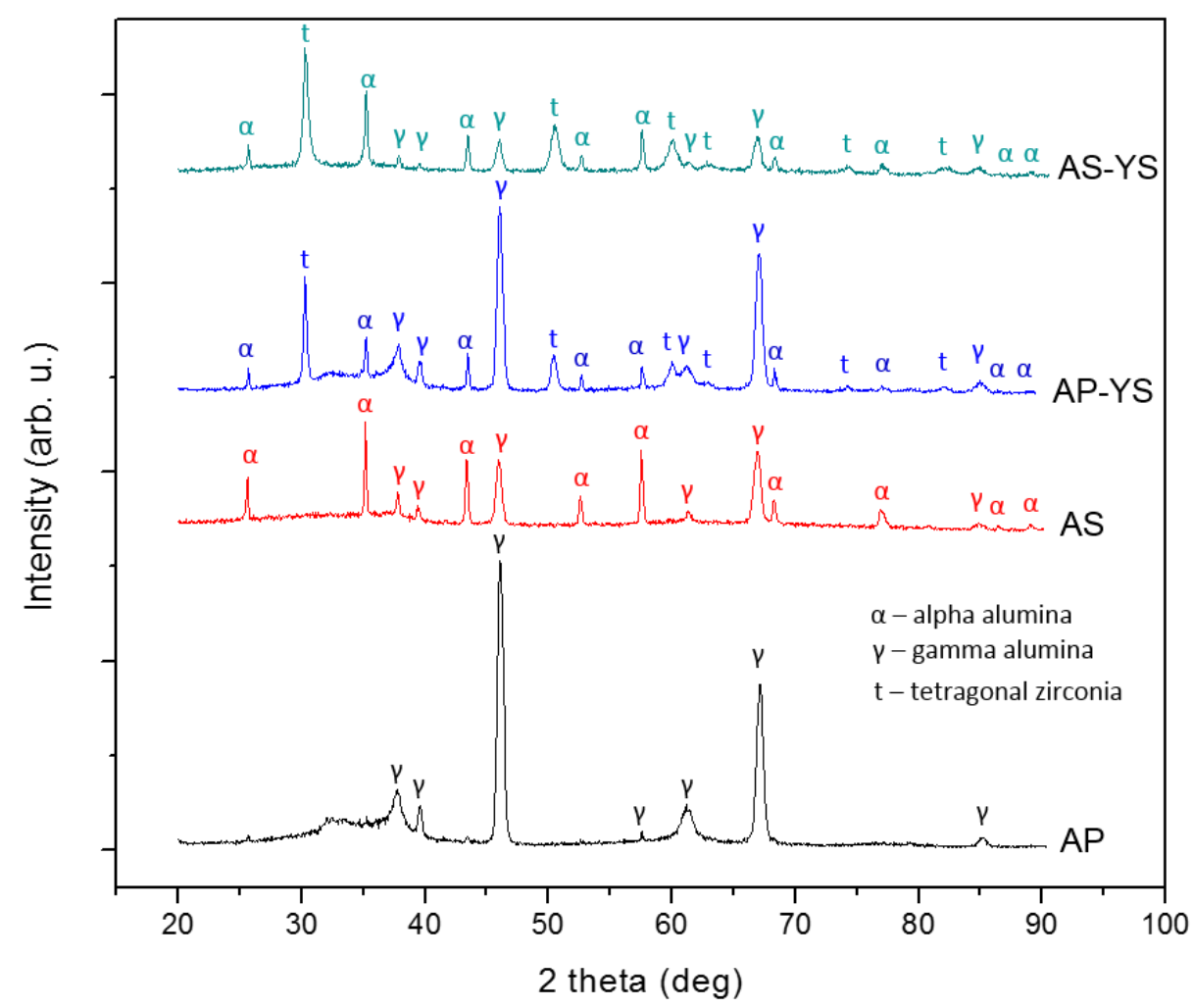

Figure 4 XRD analysis for the four coatings. $\alpha$ is the alpha alumina phase, $\gamma$ represents the gamma alumina phase and $t$ indicates the tetragonal YSZ peak 
After spraying, the plasma sprayed alumina powder (AP) coating contained only gamma alumina in contrast to all other coatings which contained a mixture of the alpha and gamma phases. This may be explained by the availability of the plasma energy exclusively for heating of the alpha alumina powder feedstock as opposed to utilization of a substantial portion of the available energy to evaporate the liquid medium in case of a suspension. Therefore, in case of the AP coating, the entire alpha alumina feedstock was melted and quenched to form gamma alumina. The hybrid AS-YS sample showed the greatest retention of the alpha phase, with only minor peaks of gamma appearing, whereas the hybrid AP-YS sample showed gamma as the dominant phase. The two hybrid coatings, AS-YS and AP-YS, yielded similar peak heights for the YSZ in comparison to other phases, implying a similar level of YSZ deposition occurred for both samples. In all cases, the tetragonal form of zirconia was identified.

The samples sprayed from feedstock partially or entirely composed of powder yielded significant amorphous humps in the XRD patterns (between 25-35 2-theta values). The alumina plasma sprayed coating (AP) showed the highest level of amorphous phase, followed by the AP-YS which showed lower amorphous levels. The degree of amorphisation also appears correlated with the level of gamma phase transformation.

\subsection{Hardness and fracture toughness}

The hardness of the as-sprayed coatings is presented in Figure 5 (a). The alumina powder coating sample, AP, yielded the highest mean hardness of $12.65 \mathrm{GPa}$. This may be explained by presence of a hard amorphous phase formed via rapid quenching as shown to be present in the XRD pattern. The coating obtained from the alumina suspension (AS) yielded a lower microhardness despite reduced porosity in the coating. This coating predominantly comprised a mixture of alpha and gamma alumina and, despite the greater presence of alpha alumina phase within the coating, the microhardness was not found to increase. The presence of YSZ addition to alumina suspension only slightly increased the microhardness by $\sim 6 \%$. However, 
considering the standard deviation measured for the samples, the three coatings made using suspension as a constituent yielded similar hardness values, notably lower than the AP sample.

(a)

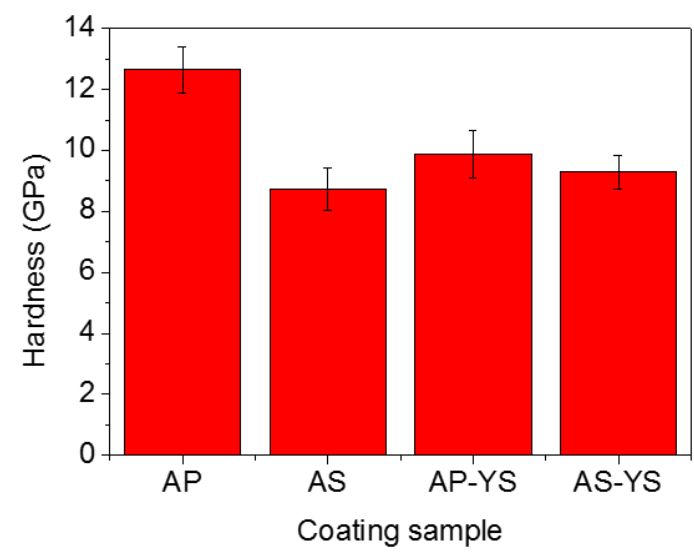

(b)

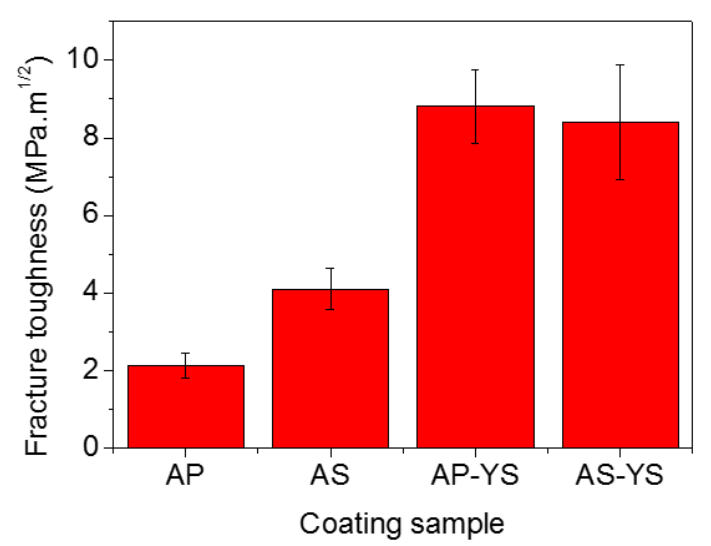

Figure 5 (a) Hardness and (b) fracture toughness of the four coatings with error bars

\section{depicting standard deviation}

The mean fracture toughness values of the coatings are shown in Figure 5 (b). The AS-YS and AP-YS samples yielded the highest toughness values at approximately $8.5 \mathrm{MPa} \cdot \mathrm{m}^{1 / 2}$. The mean toughness of the AS sample is approximately $4 \mathrm{MPa} \cdot \mathrm{m}^{1 / 2}$, with the AP sample yielding only 2 MPa.m $\mathrm{m}^{1 / 2}$. The drastically lower fracture toughness of the AP sample compared to the others is likely explained by a combination of factors. The notable formation of the amorphous phase in the AP sample is expected to contribute to lower toughness, and increased porosity also would yield lower toughness via a larger number of stress concentrators leading to enhanced crack propagation at pores [15]. Interestingly, using a suspension of alumina as opposed to powder alumina yielded twice the fracture toughness, explained by the dominance of the tougher alpha alumina in the AS coating along with lower porosity. It should also be noted that the AS-YS and AP-YS samples showed very similar toughnesses, despite the dominance of the alpha phase in the AS-YS coating, perhaps explained by the overriding contribution of the YSZ reinforcement to the toughness in comparison to the properties of the matrix. 


\subsection{Wear Testing}

Dry sliding wear testing was conducted on the polished surface of the coating samples. The wear rates (mean of two individual tests) for all samples are shown in Figure 6 (a).

(a)

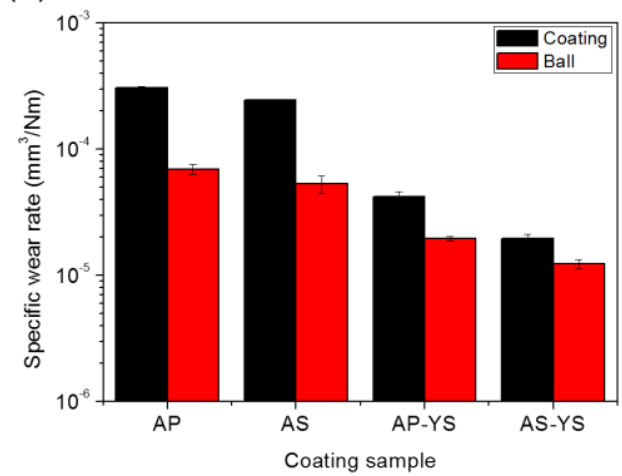

(b)

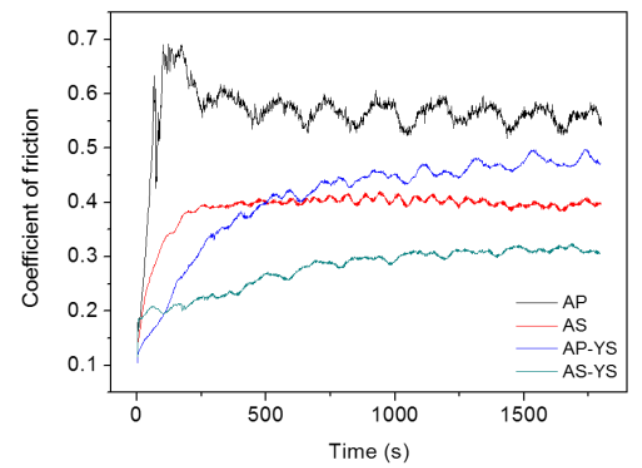

Figure 6 (a) mean specific wear rates for coatings and corresponding counterbody, with error bars depicting standard deviation and (b) coefficient of friction from wear tests

The alumina powder and suspension samples; AP and AS, yielded the highest specific wear rates at between 2 and $3 \times 10^{-4} \mathrm{~mm}^{3} / \mathrm{Nm}$, respectively. The results imply that the addition of YSZ can reduce wear rate by approximately one order of magnitude compared to alumina without YSZ. Interestingly, the AS-YS samples yielded a mean specific wear rate half that of the AP-YS sample.

The sample yielding the highest wear rate (AP) also underwent a rapid initial increase in friction coefficient to a value higher than 0.65 , followed by a decrease before attaining steady state friction characterised by a severe sawtooth pattern. All other samples, however, experienced a relatively gradual increase in friction followed by a steady state friction characterised by slight sawtooth patterns to various extents. Interestingly, both plasma sprayed samples with alumina powder were characterised by highly sawtooth friction coefficients, possibly representative of stick-slip wear behaviour. The lowest friction co-efficient was 
observed in the alumina suspension-YSZ suspension (AS-YS) coating which also showed the lowest specific wear rate in the ball-on-flat tests.

To explain the wear mechanisms, a close examination of the wear track morphology of the four coatings, as shown in the SEM images in Figure 7, can be considered.
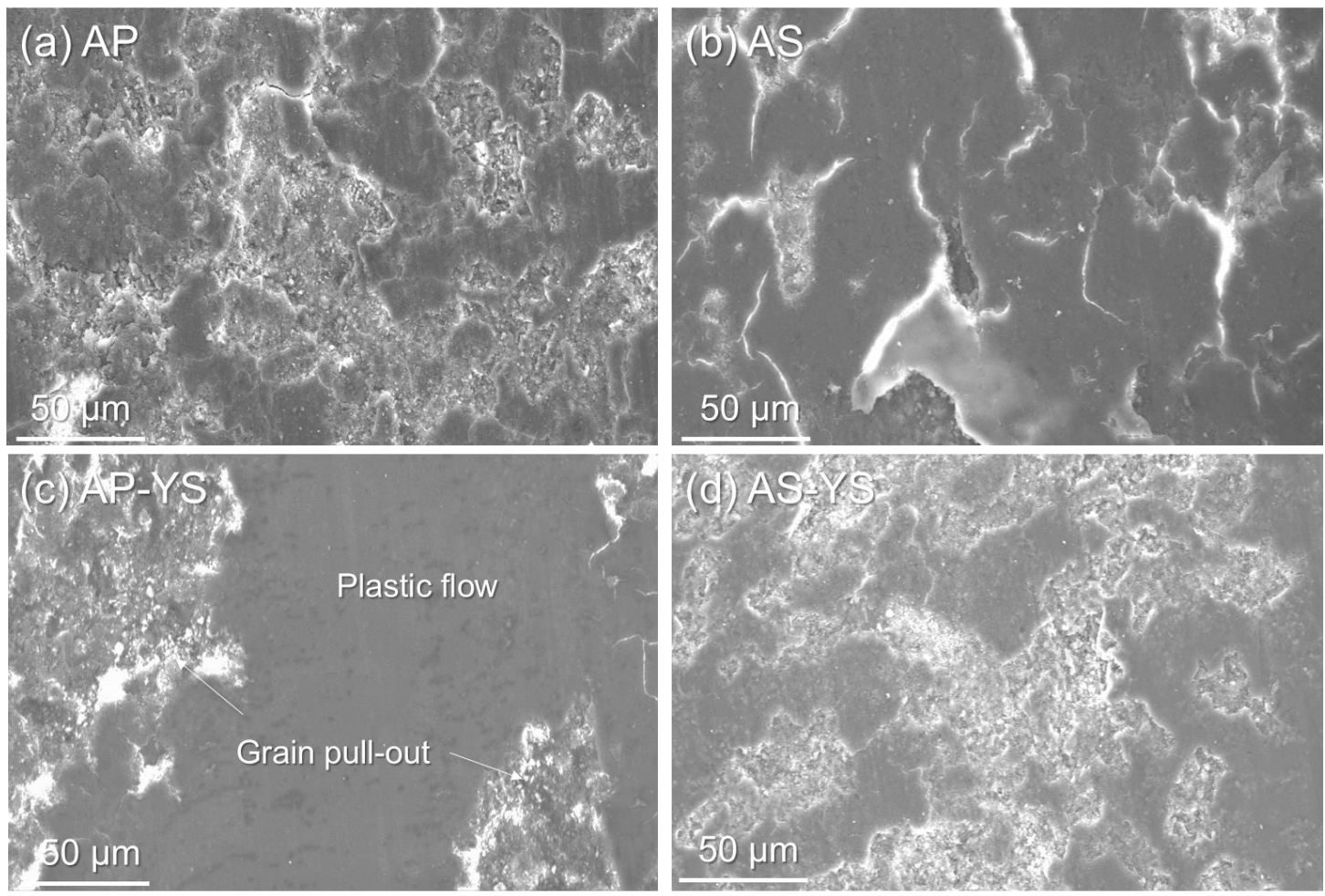

Figure 7 SE images of wear tracks on (a) alumina powder (AP) (b) alumina suspension (AS), (c) alumina powder-YSZ suspension (AP-YS) and (d) alumina suspension-YSZ suspension (AS-YS) coatings showing grain pull-out and fracture

All coating wear tracks showed evidence of a combination of brittle fracture/grain pull-out and plastic flow as the primary wear mechanisms. No particular difference in track morphology and, hence, wear mechanism was seen between the four different coating types.

\section{Discussion}

In this section the mechanical and wear properties of the plasma sprayed coatings will be considered in the context of the morphology and microstructural results presented in section 3 . 


\subsection{Coating morphology and mechanical properties}

The coating obtained from the alumina powder (AP) sample yielded the highest hardness, but lowest fracture toughness of all samples. The poorer toughness compared to the suspension alumina sample can be explained by the much $(\sim 3 \mathrm{x})$ higher porosity than the AS sample, providing more locations for stress concentration and hence enhanced crack propagation. The higher hardness may be explained by the presence of a significant level of amorphous phase. However, the hardest coating (AP) also showed the lowest fracture toughness, followed by the AS sample. This can be explained by the presence of only gamma alumina in the AP coating. Gamma alumina in HVOF sprayed coatings, for example, is known to worsen fracture toughness [16], and hence the poor toughness of the pure gamma alumina containing AP sample is perhaps to be expected.

The notably higher porosity of the AP coating compared to the three other plasma sprayed coatings can be explained by the large splat size associated with powder particle delivery of alumina in comparison to the three other samples fabricated by involving suspension delivery. Firstly, larger particles are expected to not melt as readily as finer particles. Finer particles are also likely to occupy regions of porosity left vacant due to incomplete melting of other/larger particles.

The two hybrid (YSZ containing) coatings showed the highest mean toughness. Given that zirconia is well known as a toughening agent used in ceramic matrices, this is expected. Mechanisms likely include crack deflection, crack bridging and presence of microcracks to inhibit crack propagation and hence improve toughness [8].

\subsection{Wear behaviour}


The hybrid coatings containing YSZ (AP-YS) showed a reduction in specific wear rate by an order of magnitude compared to the alumina powder plasma sprayed coatings AP, hence demonstrating the contribution of the addition of YSZ to the wear behaviour. Between the two YSZ containing samples, the AS-YS sample showed the lowest wear rate on both coating and counterbody. This difference was accompanied by a significantly reduced friction coefficient for the AS-YS sample compared to the AP-YS sample (mean of 0.31 compared to 0.47 ). The wear rates of the AP and AS samples (without YSZ) were similar and their counterbody wear rates were also significantly higher than those of the YSZ containing samples. Interestingly, the mean specific wear rate of the AP-YS was twice as high as that of the AS-YS sample, and this difference was also reflected in the counterbody wear rate. Several factors likely explain the twice as high specific wear rate for the AP-YS compared to AS-YS. In the AP-YS sample, the gamma phase is the dominant phase, in contrast to the AS-YS coating in which gamma alumina forms only a minor part of the phases present, and is instead dominated by alpha alumina, along with tetragonal zirconia. Previous work of the authors showed the difference in wear rate in SHVOF coatings, for example, can be two orders of magnitude depending on the prevalence of the gamma phase [16]. The higher porosity of the AP-YS sample may also play a significant role, with the presence of pores exacerbating the grain pull-out effect or encouraging brittle fracture via more locations of stress concentration and hence crack generation. However, it should be noted that the measured fracture toughness in this work showed no difference between the AP-YS and AS-YS samples. It is notable that the distribution of regions indicative of a plastic flow mechanism is more heterogeneous and generally larger on the AP-YS sample compared to the AS-YS coating, which may be caused by the heterogeneity of either porosity or the YSZ reinforcements seen in cross-sectional images of the coatings. 
All samples showed similar wear track morphologies, dominated by a combination of plastic flow and brittle fracture/grain pull-out. Such morphologies are typical of (SHVOF) sprayed alumina containing a large amount of gamma phase [16]. However, despite the significant variation in gamma alumina constitution in some of the coatings, the overall wear mechanism does not appear to differ strongly between samples. Hence, the lower wear rate of the YSZ containing samples is likely explained by the improved fracture toughness and the consequent lower rate of brittle fracture and grain pull out.

It is clear that despite the complete absence of the tougher alpha phase, and the lowest fracture toughness of the AP sample, its wear rate was similar to that of the AS sample. Despite the similar specific wear rates, the smoother track morphology of the AS sample does reflect a more mild wear regime taking place at least at the end stages of the wear test, and the coefficient of friction curve (Figure 6) for the AS sample is lower and more uniform, reflecting a milder regime explained by the presence of alpha alumina.

The AP sample showed an initial steep increase in friction to a high value - just below 0.7 followed by a decrease to values between 0.5 and 0.6 before stabilizing at $\sim 0.55$. This phenomenon is likely explained by an initial adhesive mechanism [17], resulting in subsequent reduction of friction after removal and smoothing of transferred material. This behaviour is similar to that seen in alumina coatings sprayed by SHVOF, and can be correlated to the presence of gamma alumina and reduced fracture toughness [16]. All other samples showed a gradual increase in friction coefficient correlating to an increase in contact area between the coating surface and the ball, followed by fluctuating friction associated with fracture and pullout of material.

It is clear from the present study that a hybrid approach of delivering alumina powder along with a YSZ suspension can be used to successfully deposit a coating via plasma spraying. Although suspension delivery of alumina along with reinforcing YSZ yielded a more refined 
coating microstructure with marginally superior wear properties, the above hybrid approach can have important implications in tailoring coating chemistry and significantly enhancing functional properties through incorporation of relatively small quantities of sub-micron or nanosized feedstock via suspensions.

\section{Conclusions}

A hybrid plasma spraying approach for depositing simultaneously a material from a powder source and another material from a suspension source, was demonstrated successfully. YSZ supplied from a suspension source was supplied along with alumina as a powder or suspension to a plasma spraying source. Porosity was significantly higher for the alumina powder coating as opposed to the alumina suspension sample, likely explained by the more complete melting of finer particles in suspension and more occupation of vacancies in the coating more readily by such particles. Porosity was higher in the alumina powder-YSZ suspension (AP-YS) sample compared to the alumina suspension-YSZ suspension (AS-YS) sample, by virtue of the higher splat density associated with suspension only delivery. Both the AP-YS and AS-YS sample yielded much higher fracture toughness and lower (one order of magnitude) wear rates compared to plasma sprayed coatings of pure alumina from powder and suspension sources. The AP-YS sample formed the undesirable gamma alumina phase to a much greater extent than the AS-YS sample, which likely contributed to its reduced wear performance. However both coating types retained some alpha alumina phase. Overall, the enhanced toughness expected and measured due to the addition of the YSZ phase to an alumina matrix yielded similar, improved wear behaviour of the YSZ-alumina coatings in comparison to the alumina coatings. Further work is recommended to optimise the parameters for the hybrid provision of two different material types in plasma spraying. 


\section{Acknowledgements}

The authors would like to acknowledge Stefan Björklund of University West for support with plasma spraying, Nicholas Curry of Treibacher Industries for providing suspensions for this study, as well as Sneha Goel for assistance with the schematic in Fig. 1.

\section{References}

[1] Lekatou A, Sioulas D, Karantzalis AE, Grimanelis D. A comparative study on the microstructure and surface property evaluation of coatings produced from nanostructured and conventional WC-Co powders HVOF-sprayed on Al7075. Surface and Coatings Technology. 2015;276:539-56.

[2] Fauchais P, Rat V, Coudert JF, Etchart-Salas R, Montavon G. Operating parameters for suspension and solution plasma-spray coatings. Surface and Coatings Technology. 2008;202:4309-17.

[3] Killinger A, Gadow R, Mauer G, Guignard A, Vaßen R, Stöver D. Review of New Developments in Suspension and Solution Precursor Thermal Spray Processes. Journal of Thermal Spray Technology. $2011 ; 20: 677$

[4] Joshi SV, Sivakumar G. Hybrid Processing with Powders and Solutions: A Novel Approach to Deposit Composite Coatings. Journal of Thermal Spray Technology. 2015;24:1166-86.

[5] Chevalier J, Gremillard L. Ceramics for medical applications: A picture for the next 20 years. Journal of the European Ceramic Society. 2009;29:1245-55.

[6] Saremi M, Valefi Z. Thermal and mechanical properties of nano-YSZ-Alumina functionally graded coatings deposited by nano-agglomerated powder plasma spraying. Ceramics International. 2014;40:13453-9.

[7] Darut G, Ageorges H, Denoirjean A, Fauchais P. Tribological performances of YSZ composite coatings manufactured by suspension plasma spraying. Surface and Coatings Technology. 2013;217:172-80.

[8] Tuan WH, Chen RZ, Wang TC, Cheng CH, Kuo PS. Mechanical properties of Al2O3/ZrO2 composites Journal of the European Ceramic Society. 2002;22:2827-33.

[9] Balasubramanian M, Malhotra SK, Gokularathnam CV. Sintering and mechanical properties of sol-gel derived alumina-zirconia composites. Journal of Materials Processing Technology. 1997;67:67-70.

[10] Hannink RHJ, Kelly PM, Muddle BC. Transformation Toughening in Zirconia-Containing Ceramics. Journal of the American Ceramic Society. 2000;83:461-87.

[11] Emrullahoglu Abi CB. 12 - Toughening mechanisms in dental composites A2 - Qin, Qinghua. In: Ye J, editor. Toughening Mechanisms in Composite Materials: Woodhead Publishing; 2015. p. 321-37.

[12] Perumal G, Geetha M, Asokamani R, Alagumurthi N. Wear studies on plasma sprayed Al2O3-40wt\% 8YSZ composite ceramic coating on Ti-6Al-4V alloy used for biomedical applications. Wear. 2014;311:101-13.

[13] Chen Y-d, Yang Y, Chu Z-h, Chen X-g, Wang L, Liu Z, et al. Microstructure and properties of Al2O3-ZrO2 composite coatings prepared by air plasma spraying. Applied Surface Science. 2017.

[14] Evans AG, Charles EA. Fracture Toughness Determinations by Indentation. Journal of the American Ceramic Society. 1976;59:371-2.

[15] Polasik SJ, Williams JJ, Chawla N. Fatigue crack initiation and propagation of binder-treated powder metallurgy steels. Metallurgical and Materials Transactions A. 2002;33:73-81.

[16] Murray JW, Ang ASM, Pala Z, Shaw EC, Hussain T. Suspension High Velocity Oxy-Fuel (SHVOF)-Sprayed Alumina Coatings: Microstructure, Nanoindentation and Wear. Journal of Thermal Spray Technology. 2016:111.

[17] Jin Y, Yang Y. Tribological behavior of various plasma-sprayed ceramic coatings. Surface and Coatings Technology. 1997;88:248-54. 
Figure captions

Figure 1 Axial feed plasma spray torch with simultaneous injection of powder and suspension feedstocks

Figure 2: Secondary electron SEM images showing cross-section views of (a) alumina powder (AP), (b) alumina suspension (AS), (c) alumina powder-YSZ suspension (AP-YS) and (d) alumina suspension-YSZ suspension (AS-YS)

Figure 3: High magnification SE images of (a) alumina power (AP), (b) alumina suspension (AS), (c) alumina powder-YSZ suspension and (d) alumina suspension-YSZ suspension and revealing YSZ as bright regions

Figure 4 XRD analysis for the four coatings. $\alpha$ is the alpha alumina phase, $\gamma$ represents the gamma alumina phase and $t$ indicates the tetragonal YSZ peak

Figure 5 (a) Hardness and (b) fracture toughness of the four coatings with error bars depicting standard deviation

Figure 6 (a) mean specific wear rates for coatings and corresponding counterbody, with error bars depicting standard deviation and (b) coefficient of friction from wear tests

Figure $7 \mathrm{SE}$ images of wear tracks on (a) alumina powder (AP) (b) alumina suspension (AS), (c) alumina powder-YSZ suspension (AP-YS) and (d) alumina suspension-YSZ suspension (AS-YS) coatings showing grain pull-out and fracture 
Table captions

Table 1 Plasma spraying parameters for alumina powder, alumina suspension, alumina powder- YSZ suspension and alumina suspension- YSZ suspension

Table 2 Mechanical properties, porosity and thickness of all coatings 